\title{
THE FORTIFICATION ASSESSMENT COVERAGE TOOLKIT (FACT)
}

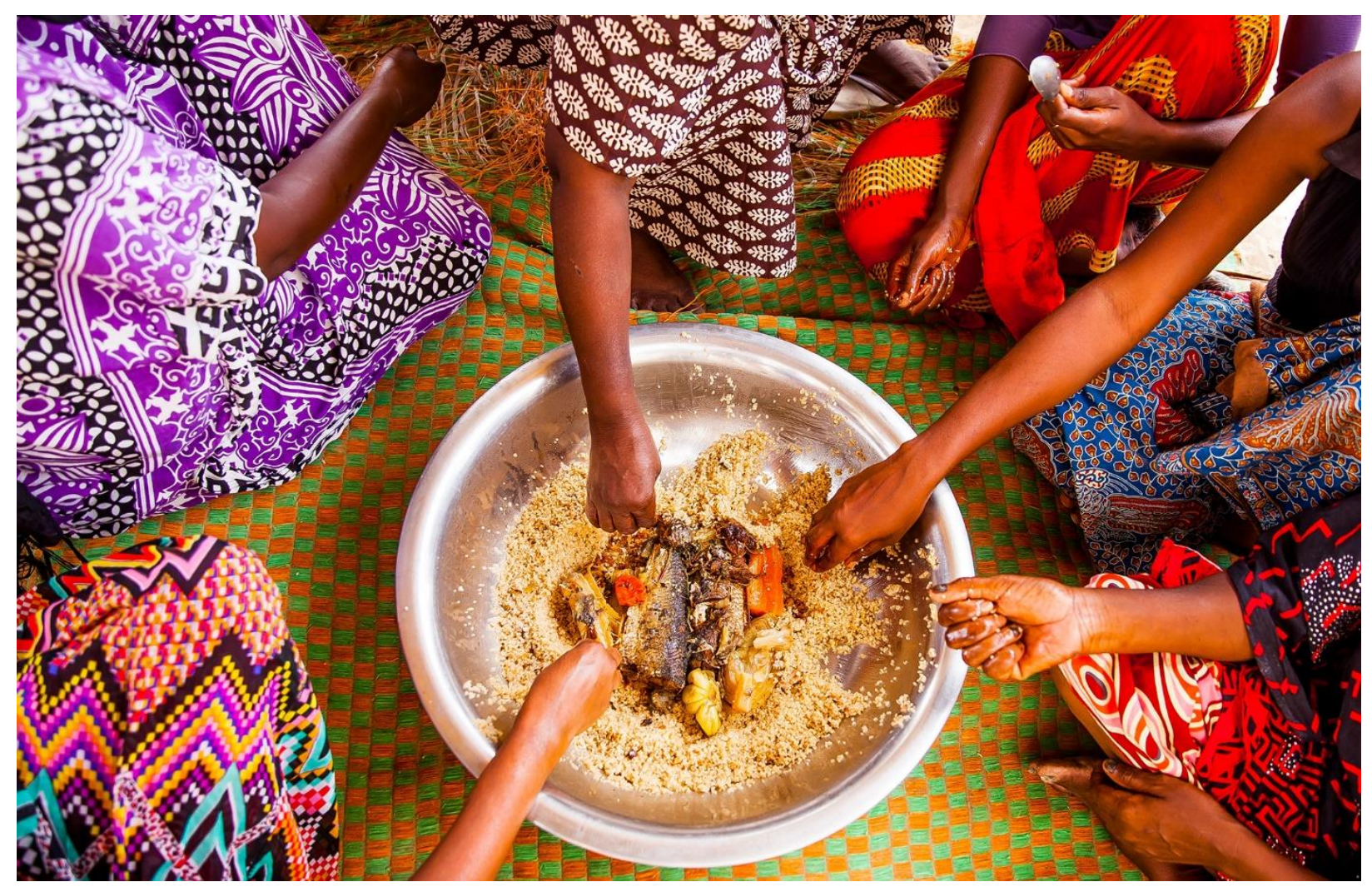

\section{GAIN Briefing Paper Series $n^{\circ} 1$}

July, 2019

Valerie M. Friesen, Mduduzi N. N. Mbuya, Lynnette M. Neufeld 


\section{ABOUT GAIN}

The Global Alliance for Improved Nutrition (GAIN) is a Swiss-based foundation launched at the United Nations in 2002 to tackle the human suffering caused by malnutrition. Working with governments, businesses and civil society, we aim to transform food systems so that they deliver more nutritious food for all people, especially the most vulnerable.

\section{Recommended citation}

Friesen VM, Mbuya MNN, and Neufeld LM. The Fortification Assessment Coverage Toolkit (FACT). Global Alliance for Improved Nutrition (GAIN). Breifing Paper Series \# 1. Geneva, Switzerland, 2019. DOI:

https://doi.org/10.36072/bp.1

\section{() The Global Alliance for Improved Nutrition (GAIN)}

This work is available under the Creative Commons Attribution-Non-Commercial-Share Alike 4.0 IGO licence (CC BY-NC-SA 4.0 IGO; https://creativecommons.org/licenses/by-nc-sa/4.0/). Under the terms of this licence, you may copy, redistribute and adapt the work for non-commercial purposes, provided the work is appropriately cited, as indicated below. In any use of this work, there should be no suggestion that GAIN endorses any specific organisation, products or services. The use of the GAIN logo is not permitted. If you adapt the work, then you must license your work under the same or equivalent Creative Commons license. The contributions of third parties do not necessarily represent the view or opinion of GAIN.

\section{Acknowledgements}

We thank the following organisations for their involvement in the design, testing, and refinement of the FACT method: Brixton Health, Centers for Disease Control and Prevention International Micronutrient Malnutrition Prevention and Control (IMMPaCT) Program, GroundWork, Oxford Policy Management, Valid International, and Westat. We also thank Oxford Policy Management for their involvement in the development of the FACT Manual and its accompanying tools and templates. We gratefully acknowledge the financial and technical support of the Bill \& Melinda Gates Foundation and the United States Agency for International Development. All photographs included in this document have been taken with consent.

\section{GAIN BRIEFING PAPER SERIES}

GAIN Briefing Paper Series provide essential information in a succinct, accessible form to support informed decision making by stakeholders in the food system to improve the consumption of nutritious, safe food for all people, especially the most vulnerable.

The Global Alliance for Improved Nutrition

(GAIN)

Rue de Varembé 7

1202 Geneva

Switzerland

T: +41227491850

E: info@gainhealth.org

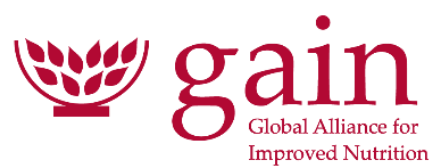




\section{SUMMARY}

Today, over 100 countries have mandatory food fortification programmes. However, information on how well those programmes are working is limited in most countries. Fortification programmes are proven to have an impact on nutrition, but this impact can only be realised if nutrient intakes increase among those with inadequate intakes. Knowing the quality, coverage, and consumption patterns of fortified foods is critical to understand whether programmes will reach their potential.

Motivated by the need for such information for its own programmes, the Global Alliance for Improved Nutrition (GAIN) developed the Fortification Assessment Coverage Toolkit (FACT) in 2013 for carrying out coverage assessments of fortification programmes.

The FACT provides standardised methods for the collection, analysis, and synthesis of data on quality, coverage, and consumption of fortified foods across countries while allowing for adaptations to meet specific country needs and contexts. Specifically, it provides step-by-step guidance on how to decide, design, and conduct a FACT survey. Information generated by a FACT survey can be used by decision makers to improve fortification programmes by documenting successes and identifying gaps.

The FACT Manual and its accompanying 10 practical tools and templates are available to download at www.gainhealth.org.

\section{KEY MESSAGES}

- Today, over 100 countries have mandatory food fortification programmes, but information on how well they are working is limited.

- To help tackle this, GAIN developed the Fortification Assessment Coverage Toolkit (FACT), which provides details on how to plan, design, implement, analyse, and report a FACT survey.

- FACT was designed to help stakeholders collect, analyse, and synthesise standardised data on quality, coverage, and consumption of fortified foods.

- FACT fills a gap in the availability of standardised tools to generate information to understand how well programmes are working and how to improve them. 


\section{WHY DOES COVERAGE MATTER?}

Today, over 100 countries have mandatory food fortification programmes (1). However, information on how well those programmes are working is limited in most countries (2). Fortification programmes are proven to have an impact on nutrition, but this impact can only be realised if nutrient intakes increase among those with inadequate intakes.

The quality of fortified foods and the consumption patterns-that is, who consumes it (e.g. rural or poor groups), where it comes from (e.g. industrial or home production), and how much is consumed and how often-are critical to understand whether programmes will reach their potential.

Motivated by the need for such information for its own programmes, the Global Alliance for Improved Nutrition (GAIN) developed the Fortification Assessment Coverage Toolkit (FACT) in 2013 for carrying out coverage assessments of fortification programmes $(3,4)$.

\section{WHAT IS THE FORTIFICATION ASSESSMENT COVERAGE TOOLKIT (FACT)?}

The FACT is a Toolkit that provides standardised methods for the collection, analysis, and synthesis of data on quality, coverage, and consumption of fortified foods across countries. Specifically, it provides step-by-step guidance on how to plan, design, implement, analyse, and report a FACT survey. The Toolkit consists of a manual and 10 practical tools and templates (4). The FACT Manual was designed to provide guidance at each link in the nutrition data value chain, from prioritisation to decision making (Figure 1) (5).

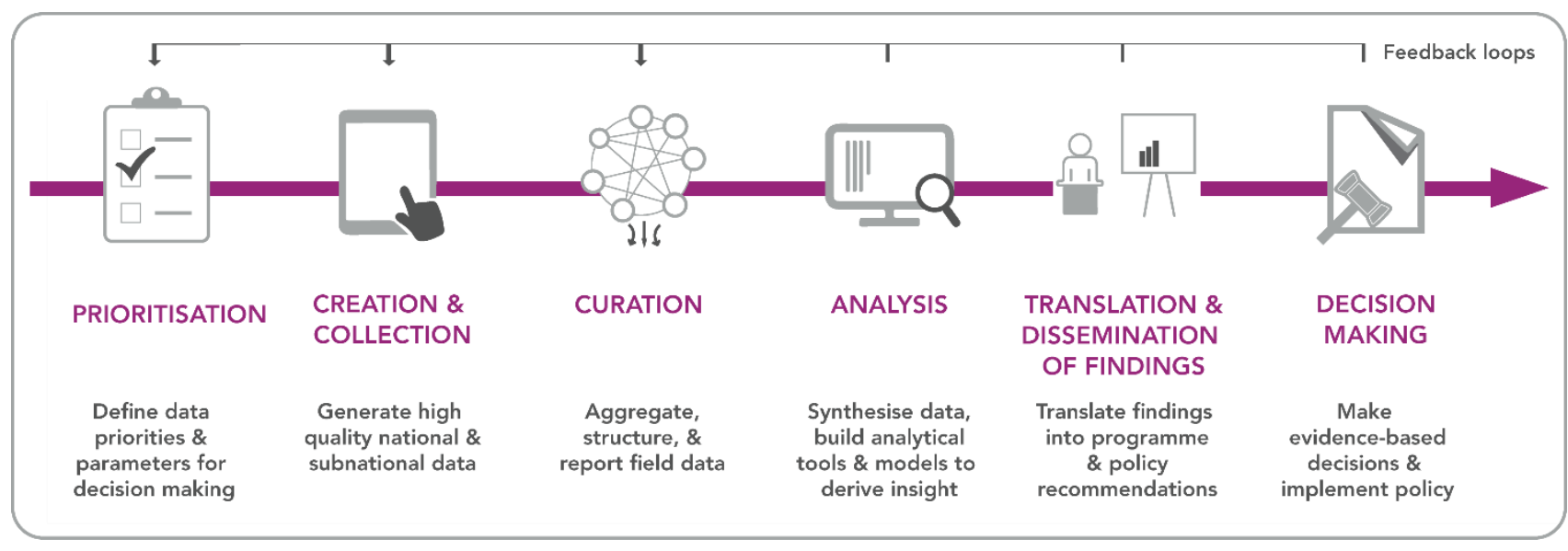

Figure 1: Nutrition data value chain. (Adapted from the 2017 Global Nutrition Report (5)).

In 2013, the initial FACT method was pilot-tested in Ghana (6). From 2013-2017, it was deployed and refined across 16 countries with large-scale fortification programmes (i.e. focused on staple foods and/or condiments) and five countries with targeted fortification programmes (i.e. focused on foods for infants and children).

In 2018, FACT coverage indicators were successfully pilot-tested in national Performance Monitoring and Accountability (PMA) 2020 surveys in Burkina Faso and Kenya. This confirmed their potential for inclusion in large household surveys, such as Demographic and Health Surveys (DHS) and Multiple Indicator Cluster (MICS) Surveys. 


\section{HOW DOES IT WORK?}

The FACT method focuses on three main questions:

1. Is a fortified food available and meeting the quality standards?

2. Are the population groups with the greatest need and potential to benefit from fortification (e.g., rural, poor, or food insecure populations, or those with low dietary diversity) consuming enough fortified foods for there to be impact?

3. To what extent are fortified foods contributing to nutrient intakes in the population and in specific groups at highest risk?

A FACT survey can be commissioned as a unique survey, or FACT indicators can be added to other data collection efforts where fortification and/or its outcomes are of interest (e.g., a nutrition survey or surveillance system).

\section{HOW CAN THE RESULTS BE USED?}

Information generated by a FACT survey can be used by decision makers to improve fortification programmes by documenting successes and identifying gaps (Figure 2).

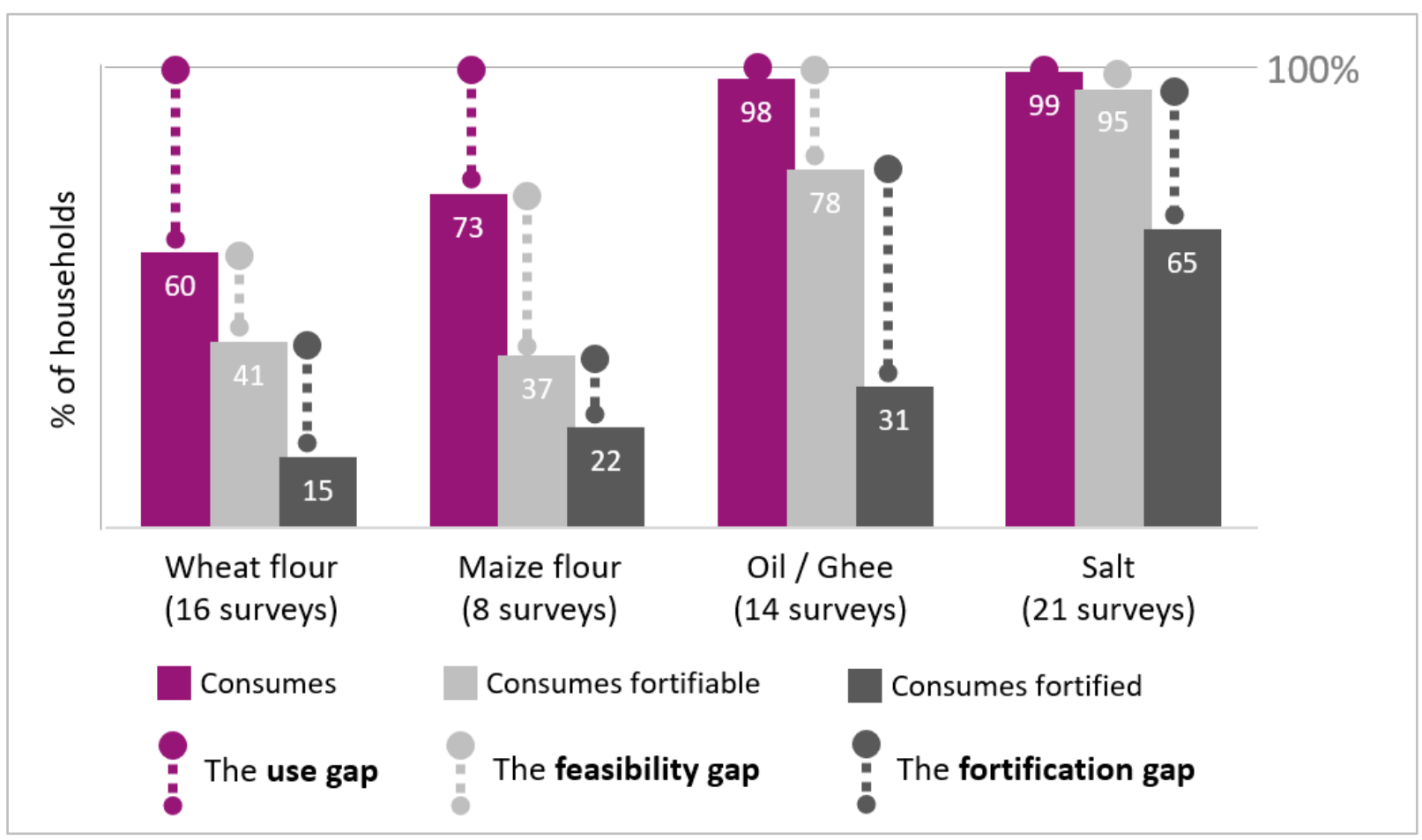

Figure 2: Aggregated FACT coverage data from on-going fortification programmes highlight several major gaps in programme design and implementation (GAIN analysis) (7-9).

For example, the use gap highlights the extent to which foods that are widely consumed have been selected for inclusion in a programme. The feasibility gap highlights the extent to which the programme was well designed, meaning it selected foods to fortify based on those that are used in a fortifiable form by a high proportion of households. The fortification gap highlights one element of how well the programme is being implemented. 
Recent FACT household coverage results were found to be actionable and to drive programmatic and policy decisions (Box 1).

\section{BOX 1. FACT HOUSEHOLD COVERAGE RESULTS WERE FOUND TO BE ACTIONABLE AND TO DRIVE PROGRAMMATIC AND POLICY DECISIONS}

In Nigeria in 2017, FACT results revealed universal coverage of fortifiable bovillon in Ebonyi and Sokoto states (>99\%). These findings were used to advocate for bovillon as a fortification vehicle, which led to efforts now being scaled up in West Africa.

In Pakistan, wheat flour is consumed by nearly $100 \%$ of the population. In 2017 , FACT revealed that a large proportion of the population (40-68\%, varying by province) consumed flour that is milled at small-scale chakki mills that are currently not included in the fortification programme. This resulted in a feasibility assessment of chakki mill fortification to determine if the scope of the programme should be expanded.

In Nigeria and Tanzania in 2015, FACT revealed that some foods chosen for fortification (maize flour and edible oil) had little potential for impact (i.e. a large feasibility gap), while others (wheat flour and salt) had high potential but needed action to improve compliance (i.e. close the fortification gap). Discussions were undertaken to encourage a focus on foods with potential for impact, and increased donor funding was secured for activities to improve quality and compliance for those foods.

\section{WHO IS IT INTENDED FOR?}

The Toolkit can be used by fortification programme stakeholders, such as government agencies, national and international organisations, universities, and individuals, who are responsible for planning, implementing, analysing, and reporting surveys that assess how well fortification programmes are working.

\section{WHERE CAN IT BE FOUND?}

The FACT Manual and its accompanying 10 tools and templates are available to download at www.gainhealth.org. 


\section{REFERENCES}

1. Global Fortification Data Exchange [Internet]. [cited 2019 Jul 17]. Available from: https://fortificationdata.org/

2. Neufeld LM, Baker S, Garrett GS, Haddad L. Coverage and utilization in food fortification programs: critical and neglected areas of evaluation. J Nutr. 2017;147(5):1015S-1019S.

3. Friesen, VM, Aaron, GJ, Myatt, M, Neufeld, LM. Assessing coverage of populationbased and targeted fortification programs using the Fortification Assessment Coverage Toolkit (FACT): background, toolkit development, and supplement overview. Journal of Nutrition. 2017;147(Suppl):981S-3S.

4. Friesen VM, Jungjohann S, Mbuya MNN, Harb J, Visram A, Hug J, et al. Fortification Assessment Coverage Toolkit (FACT) Manual. Global Alliance for Improved Nutrition (Geneva) and Oxford Policy Management (Oxford); 2019.

5. Development Initiatives. Global Nutrition Report 2017: Nourishing the SDGs [Internet]. Bristol, UK: Development Initiatives; 2017 [cited 2018 Nov 5]. Available from: http://globalnutritionreport.org/the-report/

6. Aaron GJ, Strutt N, Boateng NA, Guevarra E, Siling K, Norris A, et al. Assessing Program Coverage of Two Approaches to Distributing a Complementary Feeding Supplement to Infants and Young Children in Ghana. PLOS ONE. 2016;11(10):e0162462.

7. Aaron, GJ, Friesen, VM, Jungjohann, S, Garrett, GS, Neufeld, LM, Myatt, M. Coverage of large-scale food fortification of edible oil, wheat and maize flours varies greatly by vehicle and country but is consistently lower among the most vulnerable: results from coverage surveys in eight countries. Journal of Nutrition. 2017;147(Suppl):984S-94S.

8. Knowles JM, Garrett GS, Gorstein J, Kupka R, Situma R, Yadav K, et al. Household Coverage with Adequately lodized Salt Varies Greatly between Countries and by Residence Type and Socioeconomic Status within Countries: Results from 10 National Coverage Surveys. Journal of Nutrition. 2017;147(Suppl):1004S-1014S.

9. PLOS Collections: Fortification Assessment [Internet]. [cited 2019 Jul 17]. Available from: https://collections.plos.org/fortification-assessment 